\title{
Morpho-agronomic Characters Under Drought Stress and Genetic Diversity on the Local Landraces of Cowpea [Vigna unguiculata (L.) Walp] From East Nusa Tenggara Province, Indonesia
}

\author{
Dwi Setyo Rini ${ }^{1} \&$ Anni Nuraisyah ${ }^{2}$ \\ ${ }^{1}$ Research Center for Biology, Indonesian Institute of Sciences, Cibinong Science Center, Indonesia \\ ${ }^{2}$ Department of Agricultural Production, State Polytechnic of Jember, Indonesia \\ Correspondence: Dwi Setyo Rini, Research Center for Biology (RCB), Indonesian Institute of Sciences (LIPI), \\ Cibinong Science Center (CSC), Jalan Raya Jakarta, Bogor KM 46 Cibinong, West Java, 16911, Indonesia. Tel: \\ (6221)-87907636-87907604. Fax: 87907612. E-mail: dwi.setyo.rini@lipi.go.id
}

\author{
Received: January 9, 2021 \\ Accepted: February 2, $2021 \quad$ Online Published: February 15, 2021 \\ doi: $10.5539 /$ jas.v13n3p17 \\ URL: https://doi.org/10.5539/jas.v13n3p17
}

The research is financed by the $23^{\text {rd }}$ Science and Technology Research Grant, Indonesia Toray Science Foundation (ITSF).

\begin{abstract}
This study was performed to reveal the morpho-agronomic characters under drought and genetic diversity using SRAP (Sequence-related amplified polymorphism) marker on local landraces of cowpea (Vigna unguiculata (L). Walp) collected from East Nusa Tenggara Province, Indonesia. Data on drought response indexes according to the dry matter production of cowpea plants classified Carolina and Pinu Pahar as drought-sensitive and drought-tolerant cowpea genotypes, respectively. The assessment of the genetic diversity of cowpea genotypes was performed by using 25 SRAP combination primers. A total of 250 bands were produced by which 245 bands (98\%) were polymorphic. The value of PIC (Polymorphic Information Content) of SRAP primers in this study varied from the highest value (0.97) to the lowest value $(0.71)$ generated by primer pairs Me4-Em1 and Me3-Em4, respectively, with an average of PIC 0.87. An unweighted pair group method based on arithmetic averages (UPGMA) in this study was performed according to Nei and Li's similarity index. The analysis of UPGMA and PCoA successfully separated Carolina and Pinu Pahar genotypes into different clusters. The result of the Mantel test showed that there was no significant correlation between the independent morpho-agronomic analysis and SRAP molecular matrix data.
\end{abstract}

Keywords: cowpea, drought stress, genetic diversity, morpho-agronomic characters, SRAP marker

\section{Introduction}

Cowpea (Vigna unguiculata (L.) Walp) is an annual herbaceous plant belonging to the Fabaceae family. Cowpea is a diploid $(2 n=22)$ with an estimated genome size of about 620 million base pairs (Chen et al., 2007). This plant is also known as one of the important legume crops which is mainly grown in a wide range of tropical and sub-tropical areas by small-scale farmers (Gupta et al., 2010; Vasconcelos et al., 2010; Jayathilake et al., 2018). Cowpea has a strong contribution to nutritional security according to its function as staple food and feedstuff (Himani et al., 2016). The global production of cowpea in 2017 is reported to reach 8.1 million tons of dried cowpea (FAOSTAT, 2019). The high nutritional content, particularly the protein content in cowpea grain $(20-40 \%)$ is being the reason for the use of this plant as an affordable protein source in daily human diets, whereas the plant residue is equally useful for animal feed (Singh et al., 2003). Cowpea also contributes to improving soil fertility through nitrogen fixation (Santos et al., 2017; Simunji et al., 2019). The inter-cropping and rotation systems of cowpea with other crop plants, such as cassava and cereals, consequently help to increase plant productivity (Dahmardeh et al., 2009; Albuquerque et al., 2015). Besides its high nutritional content and the ability for nitrogen fixation, cowpea also functions as a ground cover to protect the soil from erosion and to suppress weed growth and expansion (Inaizumi et al., 1999). 
Drought is a major environmental constraint for agriculture that affects the growth and development of plants (Taishi et al., 2006; Zhang et al., 2006; Harb et al., 2010; Rini, 2019). As a sessile organism, plants have evolved a wide range of mechanisms for fine-tuning response to environmental stresses (Valliyodan \& Nguyen, 2006; Shinozaki \& Yamaguchi-Shinozaki, 2007). The reduction of water intake by the plant during water deficit leads to the reduction of the plant yield and productivity as its effect during the plant's life cycle, such as in the vegetative phase, the reproductive phase, and the end of plant cycle phase (Serraj et al., 2004). Under water deficit, decreasing cell growth is considered as one of the most effects caused by water deficit in plants (Anjum et al., 2011). Water shortage can inhibit cell enlargement by suppressing cell expansion and cell growth due to low turgor pressure during water deficit (Tardieu et al., 2014). Therefore, the reduction in turgor pressure caused by reduced water potential will induce the interruption of the water flow from the xylem to the surrounding of elongating cells. However, the maintenance of turgor pressure above a particular threshold seems to be essential for the plant to continuously grow under water stress (Iannucci et al., 2000).

Genetic diversity refers to the diversity of the same species generated by a different genotype, which further produces varying phenotypes. It also can be interpreted that genetic diversity occurs due to the variation of inherited characters found in the population of a species (Bhandari et al., 2017). In the plant species, this term is then covering the diversity of crop wild relatives (CWR), accessions, landrace, and neglected and underutilized species (NUS). Genetic diversity which may provide the pool of novel traits, is precious for plant breeders to develop a new improved cultivar with its high yield and having the ability to combat the environmental constraints (Govindaraj et al., 2015). On the other hand, genetic diversity is being an important asset in the success of plant breeding programs through the selection of the set of parental genotypes (Bhandari et al., 2017).

Assessment of genetic diversity in plant species provides basic information for further utilization. In addition, it also functions to remove duplicate organisms having the same genetic material for conservation and evaluation purposes (Doumbia et al., 2014). Sequence-related amplified polymorphism (SRAP) is one of the PCR-based markers developed by Li and Quiros (2001). The SRAP marker would be a potential tool for estimating the genetic diversity of plant species in the genomic era. SRAP is a dominant marker, and its use is very simple, inexpensive, and effective for generating genomic fragments with high reproducibility and versatility (Robarts \& Wolfe, 2014). This marker particularly amplifies the coding regions of the genome using a pair of forward and reverse primers, in which each primer comprises 17 or 18 base nucleotides long. In every SRAP primer, there is a section called as core sequence which is composed of 13-14 bases, where the first 10 or 11 bases starting at the $5^{\prime}$ end are the filler sequences, and then is followed by the sequence CCGG- for forward primer or -AATT for reverse primer. Three selective nucleotides (random) are added at the 3' end primer (Li \& Quiros, 2001; Budak et al., 2004).

Since cowpea is grown in East Nusa Tenggara Province, Indonesia with irregular rainfall, it suffers considerable damage which affects its growth and productivity. This study was conducted to assess the morpho-agronomical characters of local landraces of cowpea under drought, which then the cowpea plants were arranged by the order on the level of drought-tolerant and sensitive plants. Furthermore, the level of genetic diversity of the cowpea plant was analyzed by using SRAP marker. Data obtained in this study would be useful for selecting closely related or very distinct plants for further study in the plant breeding program.

\section{Method}

\subsection{Plant Materials}

This study used local landraces of cowpea plants (Vigna unguiculata (L.) Walp) collected from several location sites in East Nusa Tenggara province, Indonesia. The geographic information of collection sites of cowpea plants is listed in Table 1. The cowpea seeds, now, are being the germplasm collection of Plant Physiology Laboratory, Research Center for Biology, Indonesian Institute of Sciences (LIPI). 
Tabel 1. Collection sites and geographical locations of cowpea genotypes

\begin{tabular}{lllll}
\hline No. & Genotype name & Collection site & Latitude (S) & Longitude (E) \\
\hline $\mathbf{1}$ & Naibonat & Naibonat District, East Nusa Tenggara Province & $9^{\circ} 34^{\prime}$ & $123^{\circ} 45^{\prime}$ \\
$\mathbf{2}$ & Carolina & Ramuk Village, East Sumba District, East Nusa Tenggara Province & $10^{\circ} 4^{\prime}$ & $120^{\circ} 8^{\prime}$ \\
$\mathbf{3}$ & Ramuk & Ramuk Village, East Sumba District, East Nusa Tenggara Province & $10^{\circ} 4^{\prime}$ & $120^{\circ} 8^{\prime}$ \\
$\mathbf{4}$ & Wai Rara & Wai Rara Village, East Sumba District, East Nusa Tenggara Province & $10^{\circ} 3^{\prime}$ & $120^{\circ} 31^{\prime}$ \\
$\mathbf{5}$ & Praing Kareha & Praing Kareha Village, East Sumba District, East Nusa Tenggara Province & $9^{\circ} 59^{\prime}$ & $120^{\circ} 2^{\prime}$ \\
$\mathbf{6}$ & Pinu Pahar & Pinupahar Village, East Sumba District, East Nusa Tenggara Province & $10^{\circ} 5^{\prime}$ & $120^{\circ} 7^{\prime}$ \\
$\mathbf{7}$ & Wanggameti & Wanggameti Village, East Sumba District, East Nusa Tenggara Province & $10^{\circ} 6^{\prime}$ & $120^{\circ} 14^{\prime}$ \\
\hline
\end{tabular}

\subsection{Growth Conditions and Morpho-agronomic Parameters}

Cowpea plants were grown in the pot-based system (Psys) and maintained in the greenhouse with temperature $30 \pm 5{ }^{\circ} \mathrm{C}$, relative humidity $60 \pm 20 \%$, and natural photoperiod. The experiment was carried out in a completely randomized design with two factors, local landraces of cowpea plants and drought stress treatments, each with 3 replications. The local landraces of cowpea plants consisted of 7 different genotypes as listed in Table 1. In this study, drought stress was performed by the treatments of irrigation periods comprised of four periods, i.e., irrigation every day (control), every two days, every four days, and every six days. The irrigation technique was performed until the pot reached full pot holding capacity. Drought treatments started to be subjected when the cowpea plants reached 2-week-old.

Morpho-agronomic characters, such as shoot and root length, shoot and root fresh weight, shoot and root dry weight, were observed on cowpea plants at the vegetative stage (5-week-old plants), the flowering stage (7-week-old plants), and the pod-filling stage (9-week-old plants). Measurement of the shoot length was conducted from the base of the plant up to the tip of the shoot. The root length was measured on the primary root, from the base of the root that borders to the base of the plant to the tip of the root. Shoot and root fresh weight were calculated on the fresh weight of shoot and root at the harvesting time. Shoot and root dry weight were analyzed on the shoots and the roots after being dried in an oven at $60{ }^{\circ} \mathrm{C}$ for 48 hours until they reached a constant weight. On the basis of these results, the ratio between the root and the shoot dry weight was calculated.

\subsection{DNA Isolation}

Total genomic DNA of cowpea plants was isolated from up to $100 \mathrm{~g}$ of leaf tissue of 2-week old seedlings using Genomic DNA Mini Kit for the plant (Geneaid Biotech Ltd) according to the manufacture's protocol. The quality and quantity of genomic DNA samples were checked through UV-Vis spectrophotometry using the NanoDrop 2000/c (Thermo Fisher Scientific). The quality of DNA samples was measured at a wavelength of 260 $\mathrm{nm}$ and $280 \mathrm{~nm}$. The ratio of absorbance at $260 \mathrm{~nm}$ and $280 \mathrm{~nm}$ which shows $\sim 1.8$ is generally accepted as the pure DNA sample. Furthermore, DNA was diluted with TE buffer for a working concentration of 50-80 ng/ $\mathrm{kl}$ and stored at $4{ }^{\circ} \mathrm{C}$ for PCR amplification.

\subsection{SRAP Finger Printing}

A total of 25 pairs of polymorphic SRAP primers as the combination from five forwards and five reverse primers (Table 2) were used to amplify the genomic DNA of cowpea plants. The SRAP primers used in this study were synthesized by Integrated DNA Technologies, Inc. PCR amplification was conducted in a reaction mixture of 10 $\mu \mathrm{l}$ volume containing $5 \mu 12 \mathrm{x}$ GoTaq ${ }^{\circledR}$ Green Master Mix (Promega), $0.5 \mu 1100 \mu \mathrm{M}$ forward primer, $0.5 \mu 1100$ $\mu \mathrm{M}$ reverse primer, $1 \mu \mathrm{l}$ of 50-80 ng genomic DNA as the template, and $3 \mu 1$ nuclease-free water. The thermal cycling conditions for PCR amplification was set on the PCR Thermal Cycler (Takara) as follows: initial denaturation at $94{ }^{\circ} \mathrm{C}$ for $5 \mathrm{~min}$, followed by five cycles of denaturation at $94{ }^{\circ} \mathrm{C}$ for $1 \mathrm{~min}$, annealing at $35^{\circ} \mathrm{C}$ for $1 \mathrm{~min}$, and elongation at $72{ }^{\circ} \mathrm{C}$ for $1 \mathrm{~min}$. In the remaining $3{ }^{\circ} \mathrm{C}$ ycles, the annealing temperature was increased to $50{ }^{\circ} \mathrm{C}$ for $1 \mathrm{~min}$ with a final elongation step at $72{ }^{\circ} \mathrm{C}$ for $7 \mathrm{~min}$ (Ferriol et al., 2003). The amplified SRAP products then were resolved on $1.5 \%$ TAE agarose gel and the electrophoresis was performed at 160 volts for about 90 minutes. A 100-bp DNA ladder (Geneaid Biotech Ltd) was used to identify the size of each band. 
Table 2. List of forward and reverse of SRAP primers

\begin{tabular}{lll}
\hline No. & Primers & Sequences $\left(\mathbf{5}^{\prime}-\mathbf{3}^{\prime}\right.$ ) \\
\hline 1 & Me1 (forward) & TGAGTCCAAACCGGATA \\
2 & Me2 (forward) & TGAGTCCAAACCGGAGC \\
3 & Me3 (forward) & TGAGTCCAAACCGGACC \\
4 & Me4 (forward) & TGAGTCCAAACCGGTAG \\
5 & Me5 (forward) & TGAGTCCAAACCGGTGT \\
6 & Em1 (reverse) & GACTGCGTACGAATTTGC \\
7 & Em2 (reverse) & GACTGCGTACGAATTGCA \\
8 & Em3 (reverse) & GACTGCGTACGAATTAGC \\
9 & Em4 (reverse) & GACTGCGTACGAATTTAG \\
10 & Em5 (reverse) & GACTGCGTACGAATTGGT \\
\hline
\end{tabular}

\subsection{Morpho-agronomic Data Analysis}

The data obtained from morpho-agronomic characters were statistically analyzed using JMP 11 statistics software. Furthermore, the resistant and sensitive genotypes were determined in cowpea plants after being subjected to the withholding of irrigation period for 20 days $(\Psi=-14.48 \pm 8.22 \mathrm{MPa})$ as the drought treatment, which then was compared with the plants in the normal condition (control). The indexes and equations for resistant and sensitive cowpea plants toward drought stress were presented in Table 3.

Table 3. The equations for drought response indexes

\begin{tabular}{ll}
\hline Drought resistant/Sensitive indexes & Equations \\
\hline Stress Sensitivity Index (SSI) & $\mathrm{SSI}=\left[1-\left(\mathrm{Y}_{\mathrm{si}} / \mathrm{Y}_{\mathrm{pi}}\right)\right] / \mathrm{SI}$ \\
Stress Tolerance Index (STI) & $\mathrm{STI}=\left(\mathrm{Y}_{\mathrm{pi}} \times \mathrm{Y}_{\mathrm{si}}\right) /\left(\mathrm{Y}_{\mathrm{p}}\right)^{2}$ \\
Mean Productivity Index (MPI) & $\mathrm{MPI}=\left(\mathrm{Y}_{\mathrm{pi}}+\mathrm{Y}_{\mathrm{si}}\right) / 2$ \\
Yield Index (YI) & $\mathrm{YI}=\mathrm{Y}_{\mathrm{si}} \mathrm{Y}_{\mathrm{s}}$ \\
Yield Stability Index (YSI) & $\mathrm{YSI}=\mathrm{Y}_{\mathrm{s}} / \mathrm{Y}_{\mathrm{p}}$ \\
Geometric Mean Productivity (GMP) & $\mathrm{GMP}=\left(\mathrm{Y}_{\mathrm{pi}} \times \mathrm{Y}_{\mathrm{si}}\right)^{0.5}$ \\
Harmonic Mean (HM) & $\mathrm{HM}=\left[2 \times\left(\mathrm{Y}_{\mathrm{pi}} \times \mathrm{Y}_{\mathrm{si}}\right) /\left(\mathrm{Y}_{\mathrm{pi}}+\mathrm{Y}_{\mathrm{si}}\right)\right]$ \\
Relative Drought Index (RDI) & $\mathrm{RDI}=\left(\mathrm{Y}_{\mathrm{si}} / \mathrm{Y}_{\mathrm{pi}}\right) /\left(\mathrm{Y}_{\mathrm{s}} / \mathrm{Y}_{\mathrm{p}}\right)$ \\
Abiotic Tolerance Index (ATI) & $\mathrm{ATI}=\left[\left(\mathrm{Y}_{\mathrm{pi}}-\mathrm{Y}_{\mathrm{si}}\right) /\left(\mathrm{Y}_{\mathrm{p}} / \mathrm{Y}_{\mathrm{s}}\right) \cdot\left(\mathrm{Y}_{\mathrm{pi}}-\mathrm{Y}_{\mathrm{si}}\right)^{0.5}\right]$ \\
Stress Susceptibility Percentage Index (SSPI) & $\mathrm{SSPI}=\left[\left(\mathrm{Y}_{\mathrm{pi}}-\mathrm{Y}_{\mathrm{si}}\right) /\left(2-\mathrm{Y}_{\mathrm{p}}\right)\right] \times 100$ \\
\hline
\end{tabular}

Note. $\mathrm{Y}_{\mathrm{pi}}$ and $\mathrm{Y}_{\mathrm{si}}$ are the biomass of a genotype at normal and stressed treatment, respectively. SI is the stress intensity as calculated by $\mathrm{SI}=1-\left(\mathrm{Y}_{\mathrm{s}} / \mathrm{Y}_{\mathrm{p}}\right)$. Ys and $\mathrm{Y}_{\mathrm{p}}$ are the mean of biomass of all genotypes under stress and normal conditions, respectively.

\subsection{Molecular Data Analysis}

The distinguished DNA bands as the amplified product of SRAP markers were scored as presence (1) and absence $(0)$. The $0 / 1$ score data was then constructed as binary matrix SRAP data. The corresponding diversity parameters, such as the number of total bands (NTB), the number of polymorphic bands (NPB), percentage polymorphism (PP), polymorphic information content (PIC), resolving power (RP), and power index (PI) as presented in Table 7, were calculated according to the matrix data. The number of total bands (NTB) was counted according to the number of the clearly amplified products of SRAP marker. The number of polymorphic bands (NPB) was calculated based on the different positions of the DNA band across the lanes. The percentage polymorphism for individual SRAP combination primer was calculated based on the ratio of NPB/NTB. The polymorphic information content (PIC) was calculated in each primer combination as $\mathrm{PIC}=\Sigma\left(1-\mathrm{P}_{\mathrm{i}}{ }^{2}\right) / \mathrm{n}$, where, $\mathrm{Pi}$ is the frequency of the ith allele, $\mathrm{n}$ is the number of bands (Milbourne et al., 1997). Resolving power (RP) value in each primer combination is the sum of band informativeness according to the formula $\mathrm{RP}=\Sigma \mathrm{Ib}$, and $\mathrm{Ib}$ $=1-(2 \times|0.5-p|)$, where, $p$ is the proportion of the total genotypes containing the band. Marker index (MI) was calculated for each SRAP primer combination according to the formula of MI $=$ PIC $\times$ npi, where npi is the number of polymorphic bands (Powell et al., 1996).

The genetic similarity in each pair of genotypes was calculated using Nei and Li's (1979) similarity index according to the matrix SRAP data. The genetic distance matrix then was utilized for cluster analysis by the 
method of an unweighted pair group method based on arithmetic averages (UPGMA) in Multivariate Statistical Package (MVSP, Version 3.22) software. The principal coordinate analysis (PCoA) of 7 local landraces of cowpea plant was calculated by using DARwin 6 software according to the SRAP data. The relationship between the independent morpho-agronomic and SRAP molecular matrix data was calculated by using the Mantel test in XLSTAT 2019 software with 1000 permutations.

\section{Results}

\subsection{Identifying Sensitive and Resistant of Cowpea Plants Toward Drought Stress Based on Morpho-agronomical Characters}

As shown in Table 4, the increasing of harvesting time resulted in the increasing number of significant differences in the parameters observed in the single or interaction source of variance. The significant differences $(\rho<0.05)$ were identified among cowpea genotypes in respect to all morpho-agronomical characters, except the root length and the root/shoot dry weight, in all harvesting times (Table 4). These results indicated that cowpea genotypes used in this study had a high degree of phenotypic diversity, thereby allowing them to be used in the screening for drought-tolerant genotypes. Similar to the variance of cowpea genotypes, drought stress treatments presented significant effects in all parameters observed, except the root length and the root/shoot dry weight, at the harvesting time on 9-week-old plants (pod-filling stage). The morpho-agronomical characters in cowpea plants showed similar trends in response to drought stress treatments in the harvesting time at 7-week-old plants and 9-week-old plants. The interaction between cowpea genotypes and drought treatments had no significant effect at the vegetative stage (5-week-old plants), but showed significant effects on shoot fresh weight and shoot dry weights parameters at the flowering stage (7-week-old plants) and the pod-filling stage (9-week-old plants).

Table 4. Statistically calculation for the growth responses of cowpea plants under drought stress

\begin{tabular}{|c|c|c|c|c|c|c|c|c|c|}
\hline Harvesting times & Source of Variance & $\mathrm{df}$ & SL & RL & SFW & SDW & RFW & RDW & $\mathrm{R} / \mathrm{SDW}$ \\
\hline \multirow{4}{*}{ 5-week plants } & Genotypes & 6 & $18431.01^{*}$ & $1364.14^{\mathrm{ns}}$ & $439.13^{*}$ & $6.32^{*}$ & $11.31^{*}$ & $0.13^{*}$ & $0.6378^{\text {ns }}$ \\
\hline & Drought stress & 3 & $17660.38^{\mathrm{ns}}$ & $215.44^{\mathrm{ns}}$ & $312.47^{*}$ & $4.4^{\mathrm{ns}}$ & $8.57^{\mathrm{ns}}$ & $0.05^{\mathrm{ns}}$ & $0.3168^{\text {ns }}$ \\
\hline & Interaction & 18 & $9360.38^{\text {ns }}$ & $1774.54^{\mathrm{ns}}$ & $224.14^{\mathrm{ns}}$ & $6.09^{\text {ns }}$ & $6.39^{\text {ns }}$ & $0.06^{\mathrm{ns}}$ & $2.1797^{\mathrm{ns}}$ \\
\hline & Genotypes & 6 & $168835.48^{*-}$ & $1616.7^{\mathrm{ns}}$ & $7687.36^{*}$ & $229.5^{*}$ & $25.57^{*}$ & $0.53^{*-}$ & $0.0304^{\text {ns }}$ \\
\hline \multirow[t]{3}{*}{ 7-week plants } & Drought stress & 3 & $15992.42^{\text {ns }}$ & $261.27^{\mathrm{ns}}$ & $2075.15^{*}$ & $35.86^{*}$ & $5.05^{*}$ & $0.09^{*}$ & $0.0018^{\text {ns }}$ \\
\hline & Interaction & 18 & $40143.4^{\mathrm{ns}}$ & $1812.11^{\text {ns }}$ & $9410.77^{*}$ & $214.89^{*}$ & $22.62^{\text {ns }}$ & $0.56^{\text {ns }}$ & $0.0504^{\mathrm{ns}}$ \\
\hline & Genotypes & 6 & $2788657.88^{*}$ & $4306.42^{\mathrm{ns}}$ & $31662.34^{*}$ & $881.14^{*}$ & $236.03^{*}$ & $4.98^{*-}$ & $0.0073^{\text {ns }}$ \\
\hline \multirow[t]{2}{*}{ 9-week plants } & Drought stress & 3 & $28913.23^{*}$ & $1103.44^{\mathrm{ns}}$ & $12484.42^{*}$ & $324.95^{*}$ & $110.53^{*}$ & $1.33^{*}$ & $0.0058^{\mathrm{ns}}$ \\
\hline & Interaction & 18 & $57730.16^{\text {ns }}$ & $3593.32^{\mathrm{ns}}$ & $14574.9^{*}$ & $451.21^{*}$ & $172.7^{\mathrm{ns}}$ & $2.64^{\mathrm{ns}}$ & $0.0703^{\text {ns }}$ \\
\hline
\end{tabular}

Note. SOV: Source of Variance; df: degree of Freedom, SL: Shoot length; RL: Root length; SFW: Shoot fresh weight; SDW: Shoot dry weight; RFW: Root fresh weight; RDW: Root dry weight; R/SDW: Root/shoot dry weight.

Statistical analysis was performed by usiang two-way ANOVA. ns $=$ not significant, $*=$ significant at $5 \%$.

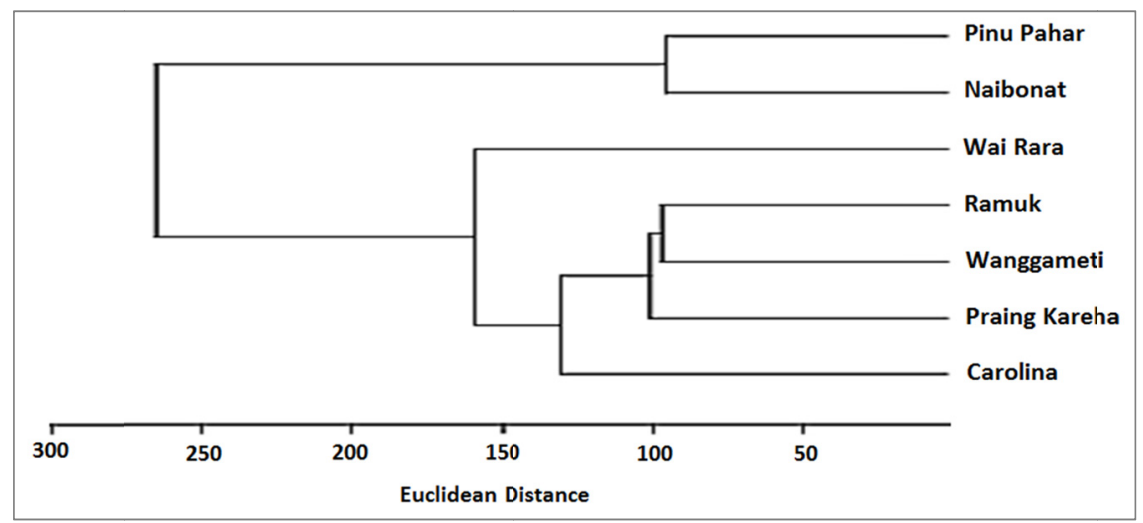

Figure 1. UPGMA-derived dendrogram on 7 local landraces of cowpea plants according to the Euclidean distance of the morpho-agronomic traits 
UPGMA-derived dendrogram of morpho-agronomic dissimilarity matrices according to the Euclidean Distance (Figure 1) enabled grouping 7 cowpea genotypes into 2 distinct clusters. The first cluster was composed of 2 cowpea genotypes Pinu Pahar and Naibonat, whereas the second cluster was formed by 5 genotypes (Wai Rara, Ramuk, Wanggameti, Praing Kareha, and Carolina).

Some mathematical equations based on normal and stress conditions (Table 3) have been proposed in order to estimate the responses of biomass dry matter production of cowpea plants toward drought stress (Table 5). The distinct characters of cowpea genotypes under drought stress conditions provided valuable information for plant selection in cowpea breeding program. It has been proposed that stress tolerance index (STI) and geometric mean productivity (GMP) are valuable for detecting the genotypes having a good performance under stress conditions (Golbashy et al., 2010). Meanwhile, plants having stress sensitivity index (SSI) values more and less than 1 indicate above and below-average susceptibility to drought stress, respectively (Guttieri et al., 2001). In other words, the genotype showing a lower value of SSI indicates more resistance to drought (Raman et al., 2012). Therefore, the genotypes with high values of STI and GMP indexes and low SSI are identified as a drought-tolerant genotype (Mohammadi et al., 2008). According to the highest values of STI and GMP, Pinu Pahar genotype was considered as a tolerant genotype to drought stress. The highest values of STI and GMP in Pinu Pahar genotype was consistently related to MPI, YI, HM, and RDI. In regard to the indexes of STI, MPI, YI, YSI, GMP, HM, and RDI (Table 5), Carolina genotype displayed the lowest values than other genotypes and showed the highest values of SSI, ATI, and SSPI indexes. Consequently, Carolina was determined as a drought-sensitive genotype.

Table 5. Drought response indexes based on biomass dry matter production in cowpea genotypes

\begin{tabular}{|c|c|c|c|c|c|c|c|c|c|c|}
\hline Genotypes & SSI & STI & MPI & YI & YSI & GMP & HM & RDI & ATI & SSPI \\
\hline Naibonat & 0.33 & 6269.74 & 79.21 & 1.09 & 0.95 & 79.18 & 79.15 & 1.12 & 396.80 & 0.03 \\
\hline Carolina & 2.64 & 3496.93 & 61.24 & 0.64 & 0.59 & 59.13 & 57.10 & 0.70 & 2232.70 & 0.19 \\
\hline Wai Rara & 1.17 & 6227.59 & 79.32 & 1.01 & 0.82 & 78.92 & 78.51 & 0.97 & 1494.31 & 0.10 \\
\hline Ramuk & 0.81 & 6229.75 & 79.11 & 1.05 & 0.87 & 78.93 & 78.75 & 1.04 & 998.91 & 0.06 \\
\hline Praing Kareha & 0.87 & 6241.54 & 79.22 & 1.04 & 0.86 & 79.00 & 78.79 & 1.02 & 1084.27 & 0.07 \\
\hline Pinu Pahar & 0.36 & 6502.65 & 80.67 & 1.11 & 0.94 & 80.64 & 80.60 & 1.12 & 448.06 & 0.03 \\
\hline Wanggameti & 0.91 & 6403.14 & 80.26 & 1.05 & 0.86 & 80.02 & 79.78 & 1.02 & 1167.27 & 0.07 \\
\hline \multicolumn{11}{|l|}{ Rank } \\
\hline Naibonat & 7 & 4 & 5 & 2 & 1 & 3 & 3 & 1.5 & 7 & 6.5 \\
\hline Carolina & 1 & 7 & 7 & 7 & 7 & 7 & 7 & 7 & 1 & 1 \\
\hline Wai Rara & 3 & 6 & 3 & 6 & 6 & 5 & 6 & 6 & 2 & 2 \\
\hline Ramuk & 5 & 5 & 6 & 3.5 & 3 & 6 & 5 & 3 & 5 & 5 \\
\hline Praing Kareha & 4 & 3 & 4 & 5 & 4.5 & 4 & 4 & 4.5 & 4 & 3.5 \\
\hline Pinu Pahar & 6 & 1 & 1 & 1 & 2 & 1 & 1 & 1.5 & 6 & 6.5 \\
\hline Wanggameti & 2 & 2 & 2 & 3.5 & 4.5 & 2 & 2 & 4.5 & 3 & 3.5 \\
\hline
\end{tabular}

Note. SSI: Stress Sensitivity Index; STI: Stress Tolerance Index; MPI: Mean Productivity Index; YI: Yield Index; YSI: Yield Stability Index; GMP: Geometric Mean Productivity; HM: Harmonic Mean; RDI: Relative Drought Index; ATI: Abiotic Tolerance Index; SSPI: Stress Susceptibility Percentage Index.

Principal component analysis was performed according to drought response indexes of cowpea plant (Figure 2). Two clusters of drought response indexes were generated in PCA. The first cluster of PCA placed drought response indexes of STI (Stress Tolerance Index), MPI (Mean Productivity Index), YI (Yield Index), YSI (Yield Stability Index), GMP (Geometric Mean Productivity), HM (Harmonic Mean), and RDI (Relative Drought Index) in the same group. The second cluster of PCA was composed of 3 drought response indexes of SSI (Stress Sensitivity Index), ATI (Abiotic Tolerance Index), and SSPI (Stress Susceptibility Percentage Index). Data shown in the PCA result (Figure 2) corresponded to Pearson correlation coefficients of drought response indexes of cowpea (Table 6). Drought response indexes of STI, MPI, YI, YSI, GMP, HM, and RDI contained in the first cluster of PCA, showed the positive and strong relationships $(\rho<0.01)$ observed between them. A similar result also presented in the second cluster where SSI, ATI, and SSPI indexes produced a positive and significant correlation each other. STI and GMP as the precious parameters for identifying resistant plant toward drought (Golbashy et al., 2010), generated a high correlation with MPI, YI, YSI, HM, and RDI in this study. Therefore, 
these indexes suggested as the strong indices to identify drought-tolerant cowpea genotypes according to the biomass dry matter production. However, the first and the second clusters of drought response indexes (Figure 2), both showed a significant negative correlation (Table 6). SSI as the strong parameter for a drought-resistance plant (Guttieri et al., 2001), showed the significant correlation with ATI and SSPI. These three indexes reflected the same information regarding plant responses under stress, which then were proposed as predictors for selecting and specifying the sensitive cowpea genotypes toward drought stress.

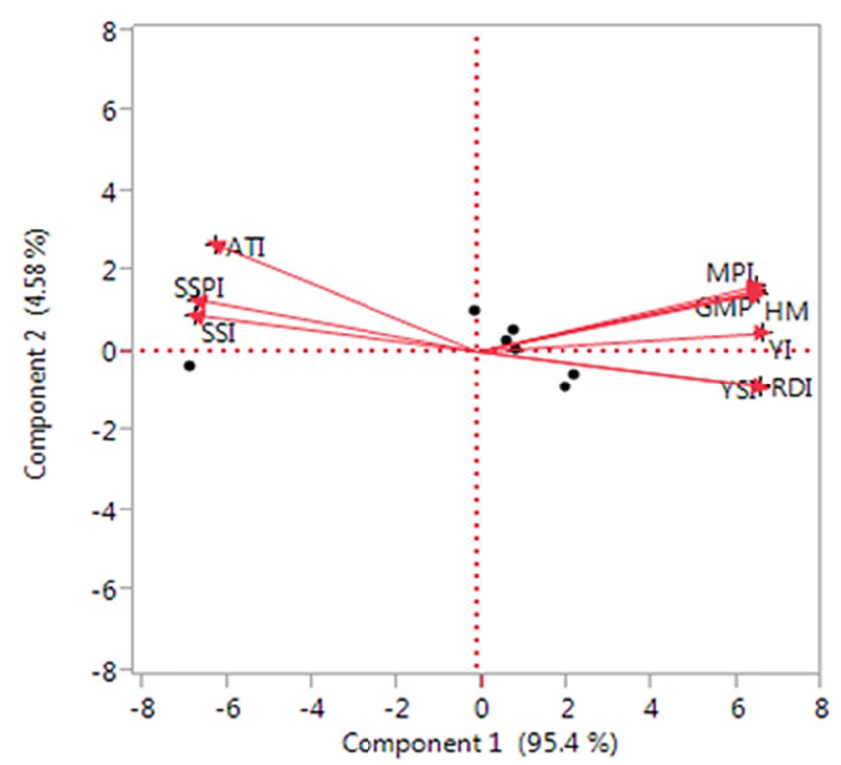

Figure 2. PCA for drought response indexes of cowpea plants

Table 6. Pearson correlation coefficients of drought stress indexes in cowpea genotypes

\begin{tabular}{lllllllllll}
\hline & SSI & STI & MPI & YI & YSI & GMP & HM & RDI & ATI & SSPI \\
\hline SSI & 1 & & & & & & & & & \\
STI & $-0.94^{* *}$ & 1 & & & & & & & & \\
MPI & $-0.93^{* *}$ & $0.99^{* *}$ & 1 & & & & & & & \\
YI & $-0.98^{* *}$ & $0.99^{* *}$ & $0.99^{* *}$ & 1 & & & & & & \\
YSI & $-0.99^{* *}$ & $0.94^{* *}$ & $0.93^{* *}$ & $0.98^{* *}$ & 1 & & & & & \\
GMP & $-0.93^{* *}$ & $0.99^{* *}$ & $0.99^{* *}$ & $0.99^{* *}$ & $0.935^{* *}$ & 1 & & & & \\
HM & $-0.94^{* *}$ & $0.99^{* *}$ & $0.99^{* *}$ & $0.99^{* *}$ & $0.94^{* *}$ & $0.99^{* *}$ & 1 & & & \\
RDI & $-0.99^{* *}$ & $0.94^{* *}$ & $0.93^{* *}$ & $0.98^{* *}$ & $0.99^{* *}$ & $0.94^{* *}$ & $0.94^{* *}$ & 1 & & \\
ATI & $0.96^{* *}$ & $-0.81^{*}$ & $-0.79^{*}$ & $-0.88^{*}$ & $-0.96^{* *}$ & $-0.80^{*}$ & $-0.81^{*}$ & $-0.96^{* *}$ & 1 & \\
SSPI & $0.99^{* *}$ & $-0.91^{* *}$ & $-0.90^{* *}$ & $-0.96^{* *}$ & $-0.99^{* *}$ & $-0.91^{* *}$ & $-0.91^{* *}$ & $-0.99^{* *}$ & $0.98^{* *}$ & 1 \\
\hline
\end{tabular}

Note. SSI (Stress Sensitivity Index), STI (Stress Tolerance Index), MPI (Mean Productivity Index), YI (Yield Index), YSI (Yield Stability Index), GMP (Geometric Mean Productivity), HM (Harmonic Mean), RDI (Relative Drought Index), ATI (Abiotic Tolerance Index), SSPI (Stress Susceptibility Percentage Index).

* Correlation is significant at $\rho<0.05$; * Correlation is significant at $\rho<0.01$.

\subsection{The Genetic Diversity of Cowpea Genotypes Based on the SRAP Markers}

In this study, a total of 25 combinations of SRAP primers enabled to amplify the genome of 7 different local landraces of cowpea plants. As shown in Table 7, the number of reproducible and clear DNA bands produced by each pair of SRAP primers varied in a range of 7 to 18 fragments with an average of 10 DNA fragments produced by each SRAP primer combination. Overall, a total of 565 bands were generated by 25 combinations of SRAP primers at 250 different fragment positions. Of these, 245 DNA fragments were polymorphic with an average percentage polymorphism of 97.47\%. All primer combinations, except Me1-Em5, Me2-Em5, Me3-Em1, Me3-Em4, and Me4-Em4, showed 100\% percent polymorphism, meaning that these SRAP primer combinations 
are adequate to identify the genetic diversity in a small number of cowpea genotypes collected from a narrow location. Of this result, the primer combination of Me3-Em4 generated the lowest percentage polymorphism of $83.33 \%$. The PIC values in this study varied among SRAP combination primers, showing the highest PIC value (0.97) and the lowest PIC value (0.71) generated by a combination of SRAP primer Me4-Em1 and Me3-Em4, respectively. The overall average of PIC values was 0.87 . The resolving power (RP) generated by SRAP primer ranged from 3.04 to 7.00 generated by primer combination of Me4-Em1 and Me5-Em1, respectively, with an average of 4.50. Meanwhile, the distinctive value of MI (marker index) in Table 7 generated an average of 8.58. The highest value of MI 16.56 was generated by SRAP primer combinations of Me1-Em1.

Table 7. SRAP analysis of cowpea genotypes

\begin{tabular}{|c|c|c|c|c|c|c|}
\hline Primers & NTB & NPB & PP (\%) & PIC & $\mathbf{R P}$ & MI \\
\hline Me1-Em1 & 18 & 18 & 100 & 0.92 & 4.00 & 16.56 \\
\hline Me1-Em2 & 10 & 10 & 100 & 0.91 & 4.00 & 9.10 \\
\hline Me1-Em3 & 10 & 10 & 100 & 0.82 & 5.80 & 8.20 \\
\hline Me1-Em4 & 10 & 10 & 100 & 0.84 & 5.20 & 8.40 \\
\hline Me1-Em5 & 10 & 9 & 90 & 0.76 & 6.60 & 6.84 \\
\hline Me2-Em1 & 11 & 11 & 100 & 0.93 & 3.45 & 10.23 \\
\hline $\mathrm{Me} 2-\mathrm{Em} 2$ & 7 & 7 & 100 & 0.88 & 4.00 & 6.16 \\
\hline Me2-Em3 & 13 & 13 & 100 & 0.9 & 4.30 & 11.70 \\
\hline Me2-Em4 & 11 & 11 & 100 & 0.82 & 5.45 & 9.02 \\
\hline Me2-Em5 & 9 & 8 & 88.89 & 0.9 & 4.22 & 7.20 \\
\hline Me3-Em1 & 7 & 6 & 85.71 & 0.85 & 5.14 & 5.10 \\
\hline Me3-Em2 & 7 & 7 & 100 & 0.86 & 4.57 & 6.02 \\
\hline Me3-Em3 & 9 & 9 & 100 & 0.93 & 3.33 & 8.37 \\
\hline Me3-Em4 & 6 & 5 & 83.33 & 0.71 & 7.00 & 3.55 \\
\hline Me3-Em5 & 11 & 11 & 100 & 0.91 & 4.18 & 10.01 \\
\hline Me4-Em1 & 4 & 4 & 100 & 0.97 & 3.50 & 3.88 \\
\hline Me4-Em2 & 11 & 11 & 100 & 0.87 & 4.00 & 9.57 \\
\hline Me4-Em3 & 13 & 13 & 100 & 0.83 & 5.54 & 10.79 \\
\hline Me4-Em4 & 9 & 8 & 88.89 & 0.78 & 6.22 & 6.24 \\
\hline Me4-Em5 & 10 & 10 & 100 & 0.92 & 3.80 & 9.20 \\
\hline Me5-Em1 & 13 & 13 & 100 & 0.92 & 3.54 & 11.96 \\
\hline Me5-Em2 & 7 & 7 & 100 & 0.89 & 3.43 & 6.23 \\
\hline Me5-Em3 & 15 & 15 & 100 & 0.91 & 3.73 & 13.65 \\
\hline Me5-Em4 & 10 & 10 & 100 & 0.86 & 3.04 & 8.60 \\
\hline Me5-Em5 & 9 & 9 & 100 & 0.88 & 4.44 & 7.92 \\
\hline Total & 250 & 245 & - & - & 112.48 & 214.5 \\
\hline Average & 10 & 9.8 & 97.47 & 0.87 & 4.50 & 8.58 \\
\hline
\end{tabular}

Note. NTB: Number of total bands; NPB: Number of polymorphic bands; PP: Percentage polymorphism; PIC: Polymorphic information content; RP: Resolving power; MI: Matrix index. 


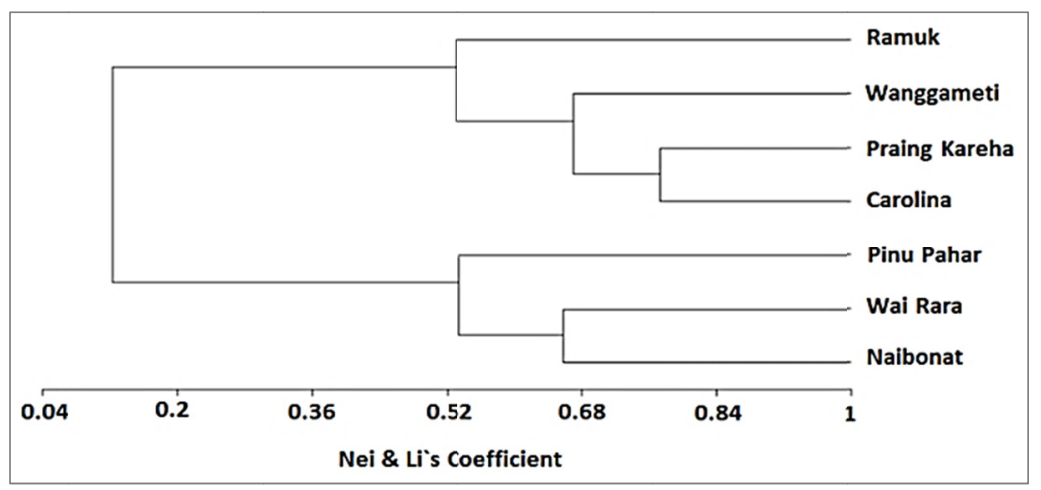

Figure 3. Dendrogram derived from UPGMA cluster analysis of 7 local landraces of cowpea plants based on Nei and Li's similarity coefficient method using 25 combination pairs of SRAP primers

The binary matrix data from 25 combinations of SRAP markers were used to assess the genetic diversity and relationship among 7 genotypes of cowpea plants used in this study. The construction of dendrogram was performed through sequential agglomerative hierarchical nested clustering and UPGMA analysis (Figure 3). The dendrogram grouped all the cowpea genotypes into two major clusters with the Nei and Li's similarity coefficient ranging from 0.123 to 0.773 . The first cluster comprised of the local landraces of Carolina, Praing Kareha, Wanggameti, and Ramuk, whereas the other comprised of Naibonat, Wai Rara, and Pinu Pahar. This UPGMA analysis separated Carolina and Pinu Pahar, which were determined as sensitive and tolerant cowpea genotypes toward drought stress, respectively, into a different cluster with the Nei and Li's similarity coefficient between them was 0.171 .

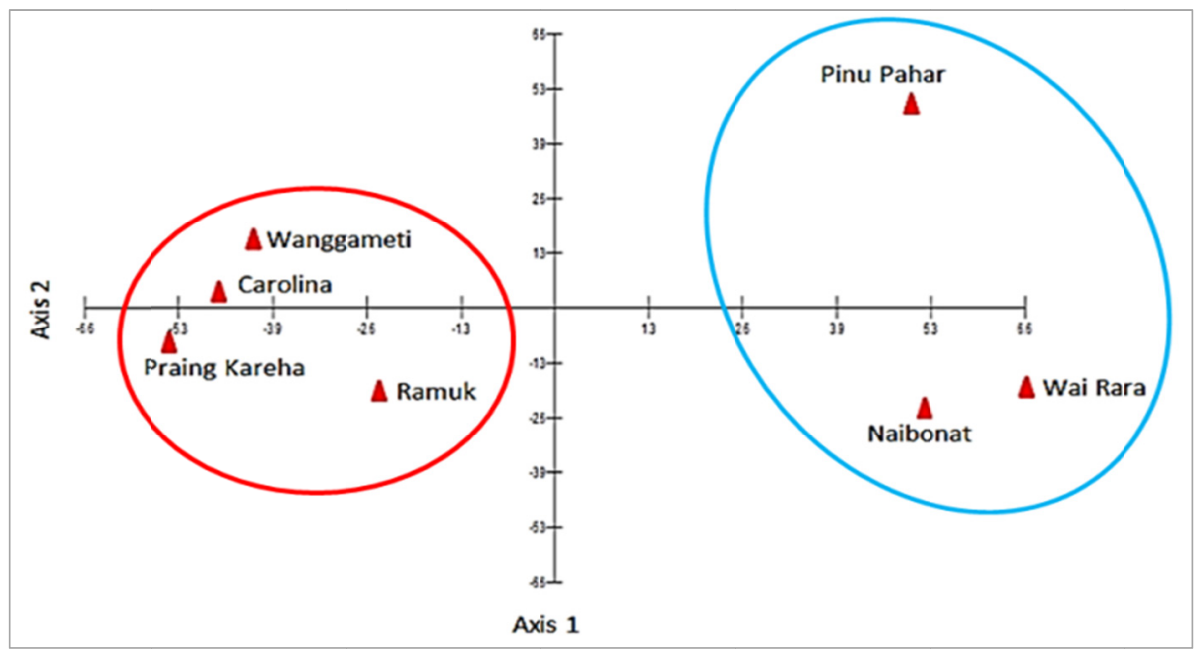

Figure 4. Principal coordinate analysis (PCoA) plot of 7 local landraces of cowpea plants generated by 25 combinations of SRAP markers

Principal coordinate analysis (PCoA) was performed by using genetic similarities data set to better understand the relationship between all the genotypes used in this study. As shown in Figure 4, PCoA also grouped 7 local landraces of cowpea plants into 2 different clusters. The PCoA result placed the local landraces of Pinu Pahar, Wai Rara, and Naibonat in a separate group from the local landraces of Wanggameti, Carolina, Praing Kareha, and Ramuk, displaying a congruent pattern with the results of UPGMA analysis (Figure 3). The PCoA also separated Carolina and Pinu Pahar as the sensitive and tolerant cowpea genotypes toward drought stress, respectively, into a different cluster. 

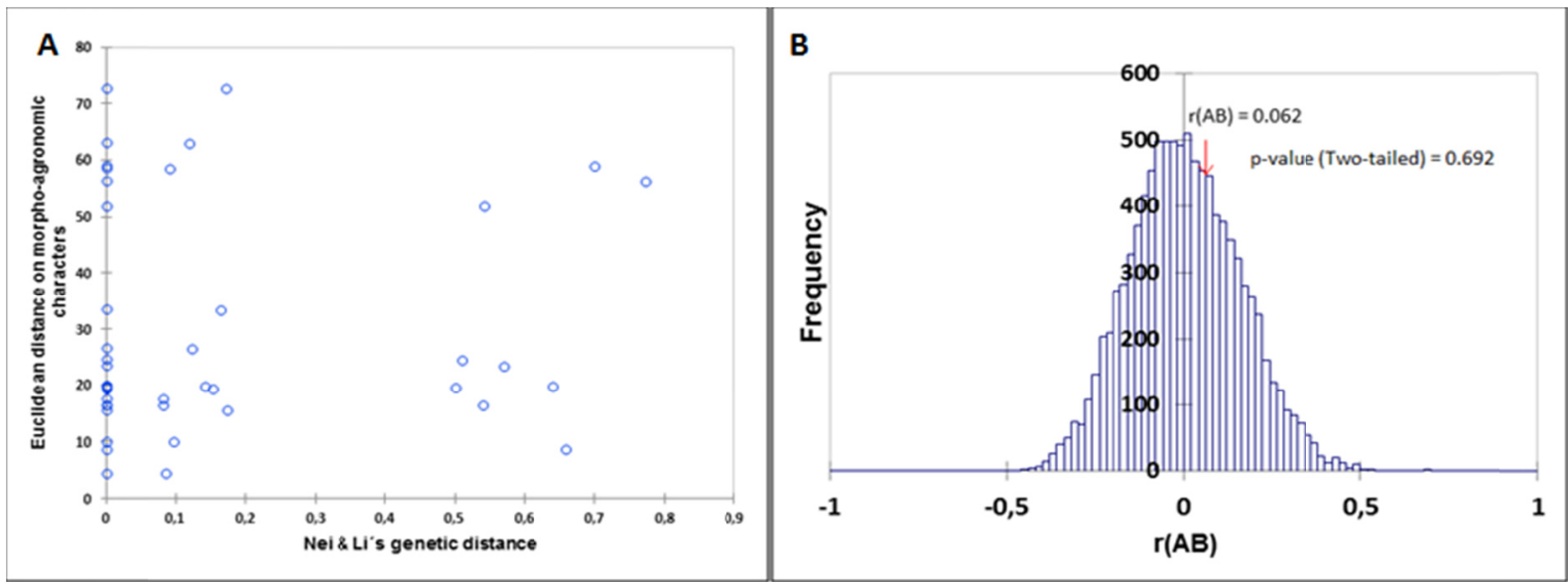

Figure 5. The relationship between the independent morpho-agronomic characters and SRAP molecular matrix data calculated by using the Mantel matrix correspondence test. (A) The regression diagram; (B) The histogram.

The test was performed by using Spearman's correlation (Mantel-test, $r=0.062 ; \rho$-value $=0.692$ )

The relationships between the morpho-agronomical distance and the Nei and Li's distance matrices obtained from SRAP markers data were calculated by using the Mantel matrix correspondence test from 10.000 permutations (Figure 5). The morpho-agronomical distances were calculated according to the Euclidean distances from morpho-agronomical parameters under drought stress. The mantel test results showed that a two-tailed $\rho$-value (0.692) was greater than the significance level alpha (0.05). Therefore, there was no significant relationship between morpho-agronomical and molecular distance matrices.

\section{Discussion}

The selection of genotypes having specific traits under drought stress has been carried out for many purposes in the plant breeding program. A better understanding regarding the plant responses under drought is being the critical aspect for determining the plant genotypes showing the desired traits. Identifying the specific character under drought stress requires considerable resources and suitable environmental conditions, therefore it can generate repeatable phenotypic character under the same conditions. ANOVA revealed significant differences among the cowpea genotypes in several morpho-agronomic characters subjected under drought conditions (Table 4).

The broad range of morpho-agronomic variation among cowpea genotypes has an important value, especially for its breeding programs. Meanwhile, the interaction between cowpea genotypes and drought treatments presented the significant effects only in the fresh and dry weight of the shoots in 9-week cowpea plants (Table 4). Accordingly, the shoot dry weight parameter was used to determine the morphological indexes for cowpea responses under drought stress (Table 5). Shoot dry weight is the acceptable parameter reflecting plant biomass of individual plant genotypes which also can estimate the plant yield (Golzarian et al., 2011).

In recent years, various methods have been proposed for identifying the resistant and sensitive plant genotypes toward drought stress. The genotypes having high yield under optimum conditions are predicted to sustain high productivity under stress (Betran et al., 2003; Mickky et al., 2019). This study successfully identified Pinu Pahar and Carolina as the drought-tolerant and drought-sensitive cowpea genotypes, respectively. Stress sensitivity index (SSI) and stress tolerance index (STI) are the appropriate indicators to determine the sensitive and tolerant plants, respectively under environmental stress conditions (Fernandez, 1992). These indexes have been successfully and widely identified the sensitive and tolerant plant toward drought stress, such as in wheat (El-Rawy \& Hassan, 2014), tomato (Metwali et al., 2016), corn (Moradi et al., 2012), and bean (Darkwa et al., 2016).

In regard to the molecular marker profile, the discriminatory power of each marker in this study was evaluated by the values of PIC, RP, and MI. PIC was calculated to identify the informativeness of a genetic marker system (Vulysteke et al., 2000) by analyzing the capacity of SRAP primers to reveal the polymorphism across all the local landraces of cowpea plants used in this study. According to Botstein et al. (1980), a molecular marker showing a PIC value of more than 0.5 is considered as a highly valuable marker to distinguish the variability of the sample analyzed. In this study, each SRAP combination primer generated PIC $>0.5$ with an average for all primers of 0.87 . In addition, the resolving power values function as a moderately accurate estimation that 
indicates the informativeness of the primer set. Nine primers out of 25 SRAP combination primers had high RP values more than the average of RP value (Table 7), presenting the high informativeness of those nine primers for distinguishing all the cowpea genotypes used in this study. As a parameter used to estimate the utility of the marker system, the Marker index (MI) value of SRAP combination primers showed an average of 8.58 with $48 \%$ of the primers were high than that of the average.

According to its floral morphology, cowpea is determined as a self-pollinating plant where the pollination process is completed before the flower opens. The cross-pollination in cowpea plant is estimated as an occasional process with the incidence rate at $<1$ or up to $2 \%$ (OECD, 2016). Therefore, cowpea is considered as a crop plant having a narrow genetic base (Afiukwa et al., 2012). Even though the cowpea plants in this study were collected from closely related areas in East Nusa Tenggara, Indonesia (Table 1), the UPGMA cluster analysis using matrix data of SRAP combination primers successfully separated 7 cowpea genotypes based on the Nei and Li's similarity coefficient (Figure 3). Pinu Pahar and Carolina as the tolerant and sensitive cowpea genotypes toward drought stress, respectively, grouped into a different cluster. This result corresponds to clustering through the Principal coordinate analysis (PCoA) plot as shown in Figure 2. Accordingly, the geographical architecture of the area where cowpea plants were collected, is being the reasons underlying the cowpea genotypes variability in this study. As stated by Gaggiotti et al. (2009), ecological and environmental factors have an important responsibility in the genetic diversity patterns of the organisms. This is because the local adaptation of the plant species to the environmental factors can lead to a case of isolation by the environment thereby prohibiting the gene flow process (Sexton et al., 2014). Several studies have reported that environmental factors play an important role in shaping the genetic diversity of the species. It is reported that the genetic diversity of Caragana microphylla as a member of Leguminosae family has been affected by environmental factors in northeast China (Huang et al., 2016). Geographic environments also affect the genetic variability and ploidy level of Erianthus arundinaceus (Zhang et al., 2017).

In this study, the Mantel test revealed that the morpho-agronomical distances have no correlation with the Nei and Li's distance matrices generated from SRAP combination primers analysis. It means that the morphological data of cowpea plants subjected under drought stress has no intercourse with matrix data generated by SRAP primers. Assessment of plant diversity by using DNA-based markers is well known as a reliable method accompanied by many features, such as simplicity, flexibility, and cost-effectiveness (Robarts \& Wolfe, 2014). Unlike the DNA marker, the morphological marker is less reliable and affected by the environment. The results in this study showing no correlation between morpho-agronomical parameters with molecular parameters in cowpea plants, correspond with other study in Aegilops geniculata (Mahjoub et al., 2009), Rosa platyacantha (Yang et al., 2016), Juglans regia (Wang et al., 2015).

\section{Conclusions}

According to the drought response indexes as the mathematics formulas used in this study, Pinupahar and Carolina have been determined as drought-resistant and drought-sensitive cowpea genotypes, respectively. The high level of PIC (Polymorphic Information Content) at the value of 0.87 generated by SRAP combination primers, indicated that SRAP marker successfully identified the genetic diversity among cowpea genotypes collected from the closely related area in East Nusa Tenggara Province, Indonesia.

\section{Acknowledgements}

The research was supported by the funding of the $23^{\text {rd }}$ Science and Technology Research Grant, Indonesia Toray Science Foundation (ITSF). The authors also acknowledge the moral support for all scientists and technical staffs at The Research Group of Plant Physiology, Research Center for Biology, Indonesian Institute of Sciences (LIPI).

\section{References}

Afiukwa, C., Onwuchekwa, O., Udu, I., Chuks, E., \& Patrick, A. (2012). Characterization of cowpea cultivars for variations in seed contents of some anti-nutritional factors (ANFs). Continental Journal of Food Science and Technology, 6(1), 25-34. https://doi.org/10.5707/cjfst.2012.6.1.25.34.

Anjum, S. A., Wang, L. C., Farooq, M., Khan, I., \& Xue, L. L. (2011). Methyl jasmonate-induced alteration in lipid peroxidation, antioxidative defense system and yield in soybean under drought. J. Agron. Crop Sci., 197(4), 296-301. https://doi.org/10.1111/j.1439-037X.2010.00468.x

Bhandari, H. R., Bhanu, A. N., Srivastava, K., Singh, M. N., Shreya, \& Hemantaranjan. A. (2017). Assessment of genetic diversity in crop plants-An overview. Adv Plants Agric Res., 7(3), 279-286. https://doi.org/ 10.15406/apar.2017.07.00255 
Botstein, D., White, R. L., Skolnick, M., \& Davis, R. W. (1980). Construction of a genetic linkage map in man using restriction fragment length polymorphisms. Am. J. Hum. Genet., 32, 314-331.

Budak, H., Shearman, R. C., Parmaksiz, I., Gaussoin, R. E., Riordan, T. P., \& Dweikat, I. (2004). Molecular characterization of buffalograss germplasm using sequence-related amplified polymorphism markers. Theor Appl. Genet., 108, 328-334. https://doi.org/10.1007/s00122-003-1428-4

Chen, X., Laudeman, T. W., Rushton, P. J., Spraggins, T. A., \& Timko, M. P. (2007). An annotation knowledge base for cowpea (Vigna unguiculata L.) methylation fltered genomic genespace sequences. BMC Bioinformatics, 8, 1-9. https://doi.org/10.1186/1471-2105-8-S3-S1

Dahmardeh, M., Ghanbari, A., Syasar, B., \& Ramroudi, M. (2009). Effect of intercropping maize (Zea mays L.) with cowpea (Vigna unguiculata) on green forage yield and quality evaluation. Asian Journal of Plant Sciences, 8(3), 235-239. https://doi.org/10.3923/ajps.2009.235.239

Dar, T., Shakeel, R., \& Verma, S. (2018). Comparative germplasm characterization of maize (Zea mays L.) in Rajouri Region of Pir Panjal Himalaya J \& K (India), based on morphological and ISSR Markers. Journal of Crop Science and Biotechnology, 21, 43-55. https://doi.org/10.1007/s12892-017-0128-0

Darkwa, K., Ambachewa, D., Mohammed, H., Asfawa, A., \& Blairc, M. W. (2016). Evaluation of common bean (Phaseolus vulgaris L.) genotypes for drought stress adaptation in Ethiopia. The Crop Journal, 4(5). https://doi.org/10.1016/j.cj.2016.06.007

de Albuquerque, J. A. A., Oliva, L. S. C., Alves, J. M. A., Uchôa, S. C. P., \& de Melo, D. A. (2015). Cultivation of cassava and cowpea in intercropping systems held in Roraima's savannah, Brazill. Revista Ciência Agronômica, 46(2), 388-395. https://doi.org/10.5935/1806-6690.20150018

Doumbia, I. Z., Akromah, R., \& Asibuo, J. Y. (2014). Assessment of cowpea germplasms from Ghana and Mali using simple sequence repeat (SSR) markers. Int. J. Agric. For., 4, 18-123.

El-Rawy, M. A., \& Hassan, M. I. (2014). Effectiveness of drought tolerance indices to identify tolerant genotypes in bread wheat (Triticum aestivum L.). Journal of Crop Science and Biotechnology, 17, 255. https://doi.org/10.1007/s12892-014-0080-7

FAOSTAT. (2019). Production-Crops-Production quantity-Cowpeas dry-2017. Retrieved from http://www. fao.org/faostat/en

Fernandez, G. C. J. (1992). Stress tolerance index-A new indiccator of tolerance. HortScience, $27,6626$. https://doi.org/10.21273/HORTSCI.27.6.626d

Ferriol, M., Picó, B., \& Nuez, F. (2003), Genetic diversity of some accessions of Cucurbita maxima from Spain using RAPD and SBAP markers. Genet. Resour. Crop Evol., 50, 227-238.

Gaggiotti, O. E., Bekkevold, D., Jorgensen, H. B., Foll, M., Carvalho, G. R., Andre, C., \& Ruzzante, D. E. (2009). Disentangling the effects of evolutionary, demographic, and environmental factors influencing genetic structure of natural populations: Atlantic herring as a case study. Evolution, 63, 2939-2951. https://doi.org/10.1111/j.1558-5646.2009.00779.x

Golbashy, M., Ebrahimi, M., Khorasani, S. K., \& Choucan, R. (2010). Evaluation of drought tolerance of some corn (Zea mays L.) hybrids in Iran. Afr. J. Agric. Res., 5, 2714-2719.

Golzarian, M. R., Frick, R. A., Rajendran, K., Berger, B., Roy, S., Tester, M., \& Lun, D. S. (2011). Accurate inference of shoot biomass from high-throughput images of cereal plants. Plant Methods, 7(2). https://doi.org/10.1186/1746-4811-7-2

Govindaraj, M., Vetriventhan, M., \& Srinivasan, M. (2015). Importance of genetic diversity assessment in crop plants and its recent advances: An overview of its analytical perspectives. Genetics Research International, 2015(2), 431487. https://doi.org/10.1155/2015/431487

Gupta, P., Singh, R., Malhotra, S., Boora, K. S., \& Singal, H. R. (2010). Characterization of seed storage proteins in high protein genotypes of cowpea [Vigna unguiculata (L.) Walp]. Physiol Mol Biol Plants, 16, 53-58. https://doi.org/10.1007/s12298-010-0007-9

Guttieri, M. J., Stark, J. C., Brien, K., \& Souza, E. (2001). Relative sensitivity of spring wheat grain yield and quality parameters to moisture deficit. Crop Sci, 41, 327-335. https://doi.org/10.2135/cropsci2001.412327x 
Harb, A., Krishnan, A., Ambavaram, M. M. R., \& Pereira, A. (2010). Molecular and physiological analysis of drought stress in Arabidopsis reveals early responses leading to acclimation in plant growth. Plant Physiology, 154(3), 1254-1271. https://doi.org/10.1104/pp.110.161752

Himani, B., Patel, A., Patel, I., Saravaiya, S. N., \& Golakiya, P. (2016). Modern cowpea breeding helps in adapting climate change. Innovative Farming, 1(4), 183-185.

Huang, W., Xueyong, Z., Xin, Z., Yulin, L., \& Jie, L. (2016). Effects of environmental factors on genetic diversity of Caragana microphylla in Horqin Sandy Land, northeast China. Ecology and Evolution, 6(22), 8256-8266. https://doi.org/10.1002/ece3.2549

Iannucci, A., Rascio, A., Russo, M., di Fonzo, N., \& Martiniello, P. (2000). Physiological responses to water stress following a conditioning period in berseem clover. Plant Soil, 223, 217-227. https://doi.org/ 10.1023/A:1004842927653

Inaizumi, H., Singh, B. B., Sanginga, P. C., Manyong, M., Adesina, A. A., \& Tarawali, S. (1999). Adoption and impact of dry-season dual-purpose cowpea in the semiarid zone of Nigeria. Ibadan: International Institute of Tropical Agriculture.

Jayathilake, C., Rizliya, V., Afka, D., Ruksheela, B., Barana, J., Srinivas, N., \& Ruvini, L. (2018). Cowpea: An overview on its nutritional facts and health benefits: Nutritional and health properties of cowpea. Journal of the Science of Food and Agriculture, 98(13), 4793-4806. https://doi.org/10.1002/jsfa.9074

Li, G., \& Quiros, C. F. (2001). Sequence-related amplified polymorphism (SRAP), a new marker system based on a simple PCR reaction, its application to mapping and gene tagging in Brassica. Theor. Appl. Genet., 103, 455-461. https://doi.org/10.1007/s001220100570

Mahjoub, A., El Gharbi, M. S., Mguis, K., El Gazzah, M., \& Brahim, N. B. (2009). Evaluation of Genetic Diversity in Aegilops geniculata Roth Accessions using Morphological and RAPD Markers. Pakistan Journal of Biological Sciences, 12, 994-1003. https://doi.org/10.3923/pjbs.2009.994.1003

Metwali, E. M. R., Carle, R., Ralf, M., Schweiggert, Kadasa, N. M., \& Almaghrabi, O. A. (2016). Genetic diversity analysis based on molecular marker and quantitative traits of the response of different tomato (Lycopersicum esculentum Mill) cultivars to drought stress. Arch. Biol. Sci., 68(2), 427-438. https://doi.org/ 10.2298/ABS150629126M

Miccky, B., Aldesuquy, H.., \& Elnajar, M. (2019). Uni- and multi-variate assessment of drought response yield indices in 10 wheat cultivars. J. Crop Sci. Biotech., 22(1), 21-29. https://doi.org/10.1007/s12892-0180221-0

Milbourne, D., Meyer, R., Bradshaw, J. E., Baird, E., Bonar, N., Provan, J., ... Waugh, R. (1997). Comparison of PCR-based marker system for the analysis of genetic relationships in cultivated potato. Mol Breeding, 3(2), 127-136. https://doi.org/10.1023/A:1009633005390

Mohammadi, A., Bihamta, M., Soloki, R.., \& Roodaki, H. R. (2008). The study of qualitative and quantitative traits of navy bean and their relation with yield in suitable and limited irrigation conditions. Journal of Agriculture Sciences, 1, 231-43.

Moradi, H., Akbari, G. A., Khavari, K. S., \& Ramshiri, H. A. (2012). Investigation of drought stress effect on morphologic traits, yield and yield components of corn (Zea mays L.) new hybrids. Greener Journal of Agricultural Sciences, 2(4), 162-177.

Nei, M., \& Li, W. H. (1979). Mathematical modelling for studying genetic variation in terms of restriction endonuclease. Proceedings National Academy of Sciences, 76, 5268-5273. https://doi.org/10.1073/pnas.76. 10.5269

OECD. (2016). Cowpea (Vigna unguiculata), in safety assessment of transgenic organisms in the environment (Volume 6: OECD Consensus Documents). OECD Publishing, Paris. https://doi.org/10.1787/9789264 253421-8-en.

Powell, W., Morgante, M., Andre, C., Hanafey, M., Vogel, J., Tingey, S., \& Rafalski, A. (1996). The comparison of RFLP, RAPD, AFLP and SSR (microsatellite) markers for germplasm analysis. Mol Breed, 2, 225-238. https://doi.org/10.1007/BF00564200

Raman, A., Verulkar, S., Mandal, N., Variar, V., Shukla, V., Dwivedi, J., ... Kumar, A. (2012). Drought yield index to select high yielding rice lines under different drought stress severities. Rice, 5, 31-43. https://doi.org/10.1186/1939-8433-5-31 
Rini, D. S. (2019). Short Communication: Sequence variation of DREB2 gene as a potential molecular marker for identifying resistant plants toward drought stress. Nusantara Bioscience, 11(1). https://doi.org/10.13057/ nusbiosci/n110107

Robarts, D. W., \& Wolfe, A. D. (2014). Sequence-related amplified polymorphism (SRAP) markers: A potential resource for studies in plant molecular biology. Appl Plant Sci., 2(7), 1400017. https://doi.org/10.3732/ apps. 1400017

Santos, J. A., Nunes, L. A. P. L., de Melo, W. J., Figueiredo, M. B. V., Singh, R. P., Bezerra, A. A. C., \& Araújo, A. S. F. (2011). Growth, nodulation and nitrogen fixation of cowpea in soils amended with composted tannery sludge. Revista Brasileira de Ciência do Solo, 35(6), 1865-1871. https://doi.org/10.1590/S010006832011000600003

Serraj, R., Krishnamurthy, L., Kashiwagi, J., Kumar, J., Chandra, S., \& Crouch, J. H. (2004). Variation in root traits of chickpea (Cicer arietinum L.) grown under terminal drought. Field Crop Res., 88, 115-127. https://doi.org/10.1016/j.fcr.2003.12.001

Sexton, J. P., Hangartner, S. B., \& Hoffmann, A. A. (2014) Genetic isolation by environment or distance: Which pattern of gene flow is most common? Evolution, 68, 1-15. https://doi.org/10.1111/evo.12258

Shinozaki, K., \& Yamaguchi-Shinozaki, K. (2007). Gene networks involved in drought stress response and tolerance. Journal of Experimental Botany, 58, 221-227. https://doi.org/10.1093/jxb/erl164

Simunji, S., Munyinda, K. L., Lungu, O. I., Mweetwa, A. M., \& Phiri, E. (2019). Evaluation of cowpea (Vigna unguiculata (L).Walp) genotypes for biological nitrogen fixation in maize-cowpea cop rotation. Sustainable Agriculture Research, 8(1), 82. https://doi.org/10.5539/sar.v8n1p82

Singh, B. B., Ajeigbe, H. A., Tarawali, S. A., Fernandez-Rivera, S., \& Abubakar, M. (2003). Improving the production and utilization of cowpea as food and fodder. Field Crops Res., 84, 169-177. https://doi.org/ 10.1016/S0378-4290(03)00148-5

Taishi, U., Fujita, M., Fujita, Y., Yamaguchi-Shinozaki, K., \& Shinozaki, K. (2006). Engineering drought tolerance in plants: Discovering and tailoring genes to unlock the future. Current Opinion in Biotechnology, 17(2), 113-22. https://doi.org/10.1016/j.copbio.2006.02.002

Tardieu, F., Parent, B., Caldeira, C. F., \& Welcker, C. (2014). Genetic and physiological controls of growth under water deficit. Plant Physiol., 164(4), 1628-1635. https://doi.org/10.1104/pp.113.233353

Valliyodan, B., \& Nguyen, H. T. (2006). Understanding regulatory networks and engineering for enhanced drought tolerance in plants. Current Opinion in Plant Biology, 9, 189-195. https://doi.org/10.1016/j.pbi. 2006.01.019

Vasconcelos, I. M., Maia, F. M. M., Farial, D. F., Campello, C. C., Carvalho, A. F. U., Moreira, R. A. M., \& de Oliveira, J. T. A. (2010). Protein fractions, amino acid composition and antinutritional constituents of high-yielding cowpea cultivars. J Food Compos Anal, 23, 54-60. https://doi.org/10.1016/j.jfca.2009.05.008

Vuylsteke, M., Mank, R., Brugmans, B., Stam, P., \& Kuiper, M. (2000). Further characterization of AFLP data as a tool in genetic diversity assessments among maize (Zea mays L.) inbred lines. Mol. Breed., 6, 265-276. https://doi.org/10.1023/A:1009656422272

Wang, H., Wu, W., Pan, G., \& Pei, D. (2015). Analysis of genetic diversity and relationships among 86 Persian walnut (Juglans regia L.) genotypes in Tibet using morphological traits and SSR markers. The Journal of Horticultural Science and Biotechnology, 90(5), 563-570. https://doi.org/10.1080/14620316.2015.11668715

Yang, S., Guo, N., \& Ge, H. (2016). Morphological and AFLP-based genetic diversity in Rosa platyacantha population in Eastern Tianshan Mountains of Northwestern China. Horticultural Plant Journal, 2(1), 55-60. https://doi.org/10.1016/j.hpj.2016.02.005

Zhang, J., Jia, W., Yang, J., \& Ismail, A. M. (2006). Role of ABA in integrating plant responses to drought and salt stresses. Field Crops Research, 97, 111-119. https://doi.org/10.1016/j.fcr.2005.08.018

Zhang, J., Yan, J., Shen, X., Chang, D., Bai, S., Zhang, Y., \& Zhang, J. (2017). How genetic variation is affected by geographic environments and ploidy level in Erianthus arundinaceus? PLoS ONE, 12(5). e0178451. https://doi.org/10.1371/journal. pone.0178451 


\section{Copyrights}

Copyright for this article is retained by the author(s), with first publication rights granted to the journal.

This is an open-access article distributed under the terms and conditions of the Creative Commons Attribution license (http://creativecommons.org/licenses/by/4.0/). 